\title{
Pioneiras da Educação no Brasil: Mulheres, professoras e intelectuais ${ }^{64}$
}

\author{
Pioneers of Education in Brazil: \\ Women, Professors and Intellectuals
}

\author{
Rita de Cássia Fraga Machado ${ }^{65}$ \\ Docente do PPGEDU/UEA - rmachado@uea.edu.br
}

Fernanda Santos Paulo ${ }^{66}$

Doutora em educação pela UNISINOS/ Instituto de Desenvolvimento Social Brava Gente, BRAVAGENTE, Brasil

\footnotetext{
$64 \quad$ Colabora para a escrita desse texto, com fichamento das obras, a estudante de pedagogia e bolsista de iniciação científica Erika Beatriz, sua pesquisa tem investigado essas questões.

65 Professora do PPGEDU/UEA. Pós-Doutora pelo Programa de Pós Graduação em Educação da Universidade do Vale do Rio dos Sinos - Bolsista PNPD/CAPES. Doutora em Educação pelo Programa de Pós Graduação em Educação da Universidade Federal do Rio Grande do Sul - E-mail: rmachado@uea.edu.br.

66 Doutora em Educação pela Universidade do Vale do Rio dos Sinos/ Unisinos, Bolsista Capes - Proex (2014-2018). Mestre em Educação pela Universidade Federal do Rio Grande do Sul/UFRGS, Bolsista CNPq (20122013). E-mail: fernandaeja@yahoo.com.br ; fernanda.paulo@pq.cnpq.br https://orcid.org/0000-0002-8022-9379.
} 
Resumo: As trajetórias teórico-práticas das intelectuais Nísia Floresta (1810-1885), Ana Maria Saul (1945) e Maria Lacerda de Moura (18871945) contribuíram e contribuem para movimentos de reinvenção da Educação nas dimensões popular, epistemológica, cultural, antropológica e política em uma perspectiva histórica. A compreensão de educação e universidade, neste texto, advém da trajetória das professoras que, em suas vidas e obras, possuem significativas contribuições para repensar a universidade na perspectiva da Educação libertadora. A sua prática profissional como mulheres intelectuais e militantes da Educação é permeada por processos de formação política. Entender esse processo na dimensão ético-política colabora no entendimento da Educação como concepção que disputa o projeto de sociedade. O objetivo deste artigo, portanto, é apresentar as trajetórias teórico-práticas dessas mulheres pioneiras da Educação brasileira. O seu trabalho é pouco conhecido pela academia, que por sua vez é machista. Desta maneira, faz-se necessário conhecer como suas trajetórias na educação brasileira possuem significativos impactos nas pesquisas educacionais, trazendo à vista o pensamento dessas mulheres, que é de suma importância para os estudos de educação e mulheres.

Palavras-chave: Pioneiras, educação brasileira, mulheres, professoras, intelectuais, feminismo.

\begin{abstract}
The theoretical-practical careers of Nísia Floresta (18101885), Ana Maria Saul (1945) and Maria Lacerda de Moura (18871945) have contributed and still do for initiatives for the reinvention of Education on popular, epistemic, cultural, anthropological and political dimensions in a historical perspective. The understanding of Education and University here comes from the careers of Professors which, in their lives and works, represent meaningful contributions to the rethinking University on the perspective of a libertarian Education. Their professional practice, as women, intellectuals and Education enthusiasts is filled with processes of political self-development. Understanding this process in the ethical-political dimension helps in the understanding of Education as a concept which competes in the field of Society projects. This article aims thus to present the theoretical-practical careers of these pioneer women in Brazilian Education. These women 's works, known by few people in a male academic context in Brazil, are essentially necessary. Knowing their careers in Brazilian Education has meaningful impacts on educational researches, bringing to visibility their thoughts is of utmost importance for the studies on Education and Women.
\end{abstract}

Keywords: pioneer women, brazilian education, women, female professors, female intellectuals, feminism. 


\section{Introdução}

presente estudo se debruça sobre o pensamento de três pioneiras da Educação no Brasil: Nísia Floresta, Maria Lacerda de Moura e Ana Maria Saul. Estudar o pensamento pedagógico dessas mulheres é fundamental para construirmos uma pedagogia feminista e popular. Todas, de forma bastante efetiva, estiveram comprometidas com a educação brasileira. Contemporâneas, trazem um debate criador e humano para a educação. Revisitá-las, portanto, é de extrema importância quando falamos em democracia. Seus pensamentos trazem um movimento inovador para a pedagogia brasileira. No pensamento de Nísia Floresta, percebemos o compromisso com a educação das meninas, a educação intelectual das meninas; com Maria Lacerda, há um desafio a ser superado com a questão da alfabetização, aliado à educação das mulheres, e, com Ana Maria Saul, percebemos um pensamento prático, ligado ao conceito de libertação humana.

As trajetórias teórico-práticas de Nísia Floresta (18101885), Ana Maria Saul (1945-) e Maria Lacerda de Moura (18871945) contribuíram e contribuem para movimentos de reinvenção da Educação nas dimensões popular, epistemológica, cultural, antropológica e política em uma perspectiva histórica. A compreensão de Educação e Universidade, no presente, advém da trajetória das pensadoras, visto que, em suas vidas e obras, encontramos significativas contribuições para repensar a sociedade na perspectiva da Educação libertadora, popular e feminista.

A prática profissional, como mulheres, intelectuais e militantes da Educação, é permeada por processos de formação política. Entender esse processo na dimensão ético-política colabora no entendimento da Educação como concepção que disputa um projeto de sociedade. A exemplo de Maria Lacerda, cujo pensamento se relacionava à luta da classe trabalhadora no período em que se encontrava. Aliás, foi uma das poucas que se inseriu no movimento de classe.

O objetivo deste artigo, portanto, é apresentar as trajetórias teórico-práticas dessas mulheres pioneiras da Educação brasileira. O seu trabalho é pouco conhecido pela academia 
machista. Desta maneira, faz-se necessário conhecer como suas trajetórias na educação brasileira possuem significativos impactos nas pesquisas educacionais, trazendo à vista o seu pensamento, que é considerado de suma importância para os estudos de educação e mulheres.

\section{Nísia Floresta (1810-1885): Pioneira da Educação Femi- nina no Brasil}

Os primeiros escritos de Nísia Floresta datam de 1831, em artigos escritos para o jornal O Espelho das Brasileiras, de Pernambuco. Ali, iniciava-se a carreira de Nísia Floresta, a escritora. Seu talento e luta marcaram sua vida literária. (ITAQUY, 2013). Nísia foi mulher literária, escritora, professora e feminista. Sobre a sua família sabe-se que:

O pai de Nísia, Dionísio Gonçalves Pinto Lisboa, um português formado em advocacia, chegou no Brasil em meados do século XIX (...) ele se apaixonou por uma viúva de nome Antônia Clara Freire, que já tinha uma filha (...) uma de três filhos que teve com o bacharel, foi registrada, em homenagem ao pai, como Dionísia Gonçalves Pinto. Nascia assim, no dia 12 de outubro de 1810, aquela que viria a tornar-se uma ilustre brasileira. (ITAQUY, 2013, p. 25).

A família de Nísia mudava-se constantemente, viviam de forma itinerante, devido à profissão do pai, pois "ele assumia causas que iam contra grandes fazendeiros e proprietários das regiões" (ITAQUY, 2013, p. 25).

Nísia teve um casamento arranjado ou não - há dúvidas - quando tinha 13 anos. Mas durou pouco tempo. Como afirma Itaquy, (2013, p. 26), “(...) uma corajosa atitude em tempos tradicionais (...) ao ver uma mulher desfazer o sagrado laço do matrimônio e a posição que as mulheres possuíam naquele contexto". 
Figura 1: Nísia Floresta

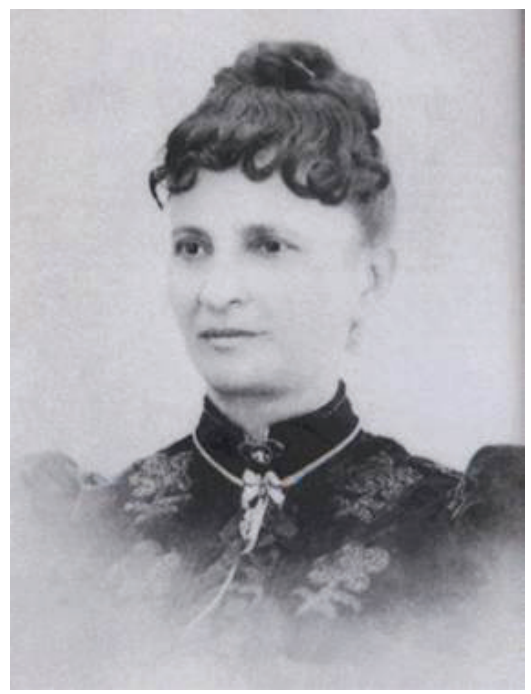

Fonte:https://www.google.com/search?q=N\%C3\%ADsia\&source=lnms\&tb$\mathrm{m}=\mathrm{isch} \& \mathrm{sa}=\mathrm{X} \& \mathrm{ved}=$ 0ahUKEwjz9rGT5qDkAhWYI7kGHRq5AQwQ_AUIESgB\#imgrc=eGvsf1jjJPrpDM:

Neste sentido, seus primeiros escritos trataram desse tema: a importância da autonomia das mulheres frente à religião e ao casamento. Para Nísia, não poderia ser a única opção da mulher se casar, pois considerava a intelectualidade importante para a sua emancipação. A pensadora não era contra o casamento, mas a favor da educação das meninas, desde jovens, ou seja, desde a sua mocidade.

No texto Opúsculo humanitário, Nísia sugere que:

Imitemos principalmente os ingleses no respeito à religião e alei, os alemães no hábito de passar e lavarem-se acima de todos os povos pelo estudo e pela reflexão, os franceses em seu espírito inventor em suas generosas inspirações civilizadoras [...] quando vemos naquelas nações tornarem-se todos os dias novas medidas para se melhorar ainda mais a educação de sua mocidade [...] (FLORESTA, 1989, p. 95).

Essa ideia pode parecer colonizadora, mas não é. Para Nísia “[...] o nosso Brasil, tão rico, tão grandiosamente excedendo a todas as nações do mundo os recursos naturais, pre- 
cisando lutar", ainda no século XIX, tinha grande dificuldade para oferecer às suas mulheres uma pequena parte das suas instruções, principalmente para as das classes mais baixas, diferente da oferecida em países da Europa e dos Estados Unidos.

Para Nísia, há, nesses países, uma educação que poderia servir de inspiração ao nosso país, o Brasil. Seria uma espécie de efeito positivo, pois tiraria essas pessoas da ignorância e, desde cedo, se investiria na educação das crianças, das meninas.

Segundo Floresta:

[...] A ignorância de nossas mulheres poderá ser um dia substituída por conhecimentos que as torne dignas de renome [...] Só a educação para produzir salutares efeitos deve acompanhar o indivíduo desde a infância (FLORESTA, 1989, p. 95).

A educação para as meninas, a sua educação intelectual, estava longe de nossa realidade, o que temos hoje é uma educação fraca e machista. O que existia era uma educação moral capitalista das meninas, o que tornava impossível adquirir o hábito das boas práticas intelectuais, que constitui a base de uma completa educação, dizia Floresta. Até então, grande parte das mães, longe de se esforçarem para diminuir os prejudiciais efeitos de tais condições, lhes ia, por seu turno, inculcando princípios demasiadamente arriscados para elas no futuro.

[...] tão graves conseqüências para a mulher, que lá se tem formado nesse pequeno ser compilador, atento, chamado menina [...] Uma mãe é, então, o quadro mais eloqüente para lhes servir de norma em sua conduta futura, o modelo que devem primeiro copiar: se esse modelo não é perfeito, como poderá a menina apresentar uma cópia perfeita? (FLORESTA, 1989, p. 96).

"A menina alemã, inglesa, e mesmo a francesa é um pequeno tesouro de graças naturais, respirando a mais pura inocência [...] E o que é da maneira brasileira?". E pensamos: qual a resposta para essa pergunta? Seria também as meninas brasileiras tesouros de graças naturais? Não, a educação de nossas meninas teve início muito tarde no Brasil. Só tivemos direito à escola pública após a constituição de $1988^{67}$, devido

\footnotetext{
67 Mesmo tendo em 1866 a primeira mulher a formar em Medicina,
} Rita Lobato, não é possível afirmar que, anteriormente à Constituição de 
à luta de muitas mulheres, incluindo a própria Nísia Floresta. Respiramos, historicamente, uma educação patriarcal, violenta e detentora de todos os vícios.

À fé que a não podemos encontrar nessas pequenas criaturas apertadas nas barbatanas de um espartilho, penteadas e vestidas à guisa de mulher, afetando-lhe os maneios e o tom, destituídas muita vez de toda a simpleza e candura. [...] ceifada tão de chofre e prematuramente pelo fatal abuso de uma moda, a quem sem escrúpulo, se sacrifica entre nós a saúde da menina (FLORESTA, 1989. p. 98).

Desta maneira, "[...] no Brasil, não se poderá educar bem a mocidade enquanto o sistema da nossa educação, quer doméstica, quer pública, não for radicalmente reformado. [...]"(FLORESTA, 1989, p. 101). Concluímos, assim, que se os mestres não possuírem as qualidades indispensáveis para o cargo de magistério, e incluírmos o feminismo como a principal qualidade, é impossível a mudança. Portanto, é da comunhão de práticas educativas, humanas, feministas e democráticas, que Floresta afirmava que poderão sair mulheres e homens capazes de firmar o renome da nação brasileira:

[...] no Brasil - onde a mulher nada é ainda pelo espírito e nenhuma liberdade goza das que utilizam e honram as mulheres do Norte [...] são as mães quase sempre o arbitro exclusivo da educação das filhas [...] transfundaram nos tenros corações de suas filhas na inata doçura e as boas qualidades do vigor, furtando-as aos exemplos de vaidade, de orgulho e dos erros que atendem a destruir ou a inutilizar a sua obra. Resignam, por amor delas, o gosto imoderado pelos prazeres do mundo [...]" (FLORESTA, 1989, p. 102).

Por fim, para uma educação feminista e popular, segundo pensadora, seria necessário "guiar as meninas em tão digno empenho e seria preciso vencer-se a fraqueza que se tem de inspirar-lhes gosto por futilidade". E "dando-lhes apenas ligeiros matizes de boa educação, só lhes atraem passageiros sucessos, que lhes preparam muitas vezes, no futuro, tristes e cruéis desilusões" (FLORESTA, 1989, p.103). Essa boa educação se fundamenta, portanto, na autonomia, na igualdade e na conquista intelectual das mulheres.

1988, o direito universal sem distinção de sexo, raça e classe social de educação era garantido. 


\section{Ana Maria Saul (1945): Mulher, professora, intelectual e Pioneira da Educação popular}

Ana Maria Saul nasceu em 25 de novembro de 1945, em São Paulo. É graduada em pedagogia, fez Mestrado e Doutorado em Educação, pela Pontifícia Universidade Católica de São Paulo. Desde 1970, é professora da PUC/SP, atuando na graduação e no Programa de Pós-Graduação em Educação. Foi colega de trabalho do Paulo Freire nessa universidade, e, atualmente, coordena a Cátedra Paulo Freire dessa instituição.

Em 1989, assumiu o cargo de coordenação da reformulação do currículo das escolas municipais da Secretaria de Educação da cidade de São Paulo, cujo secretário de educação era Paulo Freire, considerada "uma das mais competentes especialistas brasileiras em Teoria do Currículo" (FREIRE, 2006, p.24) que ele já conhecera. Ana Saul é reconhecida pelos professores e professoras pelas pesquisas acerca do tema avaliação emancipatória, fruto de seus estudos acadêmicos. A sua tese (1981 -1985) foi sobre esse tema articulado aos processos democráticos na reformulação de um curso de pós-graduação.

No âmbito universitário, Saul em desenvolvendo pesquisas na área da educação desde 1975, quando iniciou a docência na Pontifícia Universidade Católica de São Paulo. Possui experiência como pesquisadora, na gestão acadêmica e administrativa, como vice-Reitora Acadêmica dessa universidade. Além de ter passado pela coordenação do Curso de Pós-Graduação em Educação: Currículo, na condição de Vice- coordenadora. Desde 1990, é coordenadora da Cátedra Paulo Freire, igualmente Coordenadora do Grupo de Pesquisa O pensamento de Paulo Freire na educação brasileira. Esse grupo é certificado pela universidade com registro no Diretório de Pesquisa do CNPq.

Ana Maria Saul é uma das intelectuais brasileiras que vem estudando a obra de Paulo Freire e contribuindo para a construção de uma rede de pesquisadores com aderência ao pensamento freiriano e à Educação Popular. Nesse contexto, é coordenadora da rede freiriana de pesquisadores, a partir do projeto de pesquisa mencionado. 
A trajetória teórico-prática da professora é inspiração para a reinvenção da Educação Popular nas dimensões epistemológicas, culturais, antropológicas e políticas em uma perspectiva histórica. Observamos, nos seus estudos, que suas pesquisas propõem a difusão, análise crítica e aprofundamento dos estudos sobre a pedagogia de Paulo Freire, principalmente na atualidade.

A partir de seu trabalho como professora-pesquisadora, com experiência em trabalho na educação básica e superior, desenvolve temas relacionados à educação pública brasileira na atualidade, inspirada no pensamento de Paulo Freire. A abrangência de seus estudos possibilitou a criação de uma "Rede Freireana de Pesquisadores", constituída por uma equipe de dezenas de pesquisadores e colaboradores interinstitucionais. Assim, a pioneira da Educação popular freiriana vai constituindo espaços de diálogos interinstitucionais no âmbito nacional, cujo compromisso permanece com o pensamento de Paulo Freire, seu colega de Universidade, e com a educação pública brasileira.

Seus estudos e pesquisas têm repercussões em vários trabalhos realizados em teses e Dissertações (PAULO, 2018), além de publicações de textos em periódicos qualificados e livros. Considerada como uma intelectual que investiga a educação pública e as perspectivas curriculares e avaliativas, ela vem revelando a possibilidade e necessária reinvenção do pensamento de Paulo Freire na perspectiva crítica da educação.

Paulo Freire foi seu colega na Pontifícia Universidade Católica de São Paulo entre os anos de 1980 a 1997. Trabalharam juntos e dividiram sala e disciplinas durante esse percurso profissional, ambos vinculados ao Programa de Educação: Currículo.

No ano de 1998, Saul criou a Cátedra Paulo Freire, vinculada ao Programa, que tem por objetivo homenagear o educador e realizar encontros de estudos e pesquisas sobre a sua obra. A foto abaixo representa o elo entre Ana Maria Saul e Paulo Freire, cujo entendimento de Universidade, para ambos, é de um espaço de formação (SEVERINO, 2006), laços de amizade e de colaboração. 
Figura 3: Ana Maria Saul no lançamento do livro de Paulo Freire "Pedagogia: Diálogo e conflito".

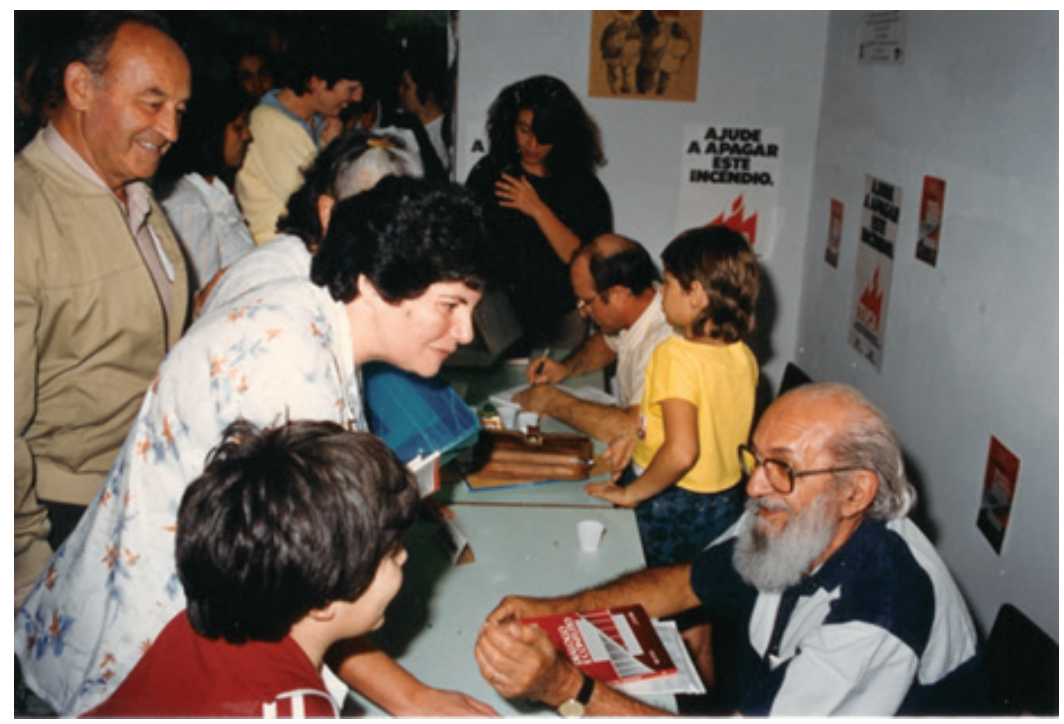

FONTE: http://acervo.paulofreire

É da ideia de Universidade de Ana Maria Saul e Paulo Freire apontada anteriormente que deriva nossa compreensão. E tal compreensão é baseada na trajetória de pesquisa e docência da professora Ana Maria Saul, marcada por histórias e memórias, muitas vezes, invisibilizadas. Suas significativas contribuições para repensar a universidade na perspectiva da Educação popular ainda são pouco conhecidas. A prática profissional, como mulher, intelectual e militante da Educação Popular, foi atravessada por processos de inserção em movimentos de formação política dentro e fora da Universidade. Desde então, a Educação Popular passa a fazer parte do seu que fazer. Em entrevista à Fernanda dos Santos Paulo (2018), nos relata, ao tratar da presença de Paulo Freire e da Educação Popular na sua trajetória teórico- prática, que:

Aí pessoas de movimentos, pessoas de diferentes tipos de, de participação na vida, na vida profissional, pública, mas que, de algum modo, ouviram falar de Paulo Freire e foram procurar a cátedra para ver se na PUC tinha esse espaço. A Educação Popular pode estar na 
Universidade. [...], ela deve ser pautada nos princípios da Educação Popular. Então eu não posso dizer, olha a minha universidade, a universidade onde eu trabalho, é uma universidade pautada na Educação popular. Não é. Ali tem uma diversidade de professores que são diferentes, mas eu tenho liberdade, na universidade que eu trabalho, de fazer o meu trabalho na perspectiva que eu acredito e quero fazer. Autonomia e compromisso político caminham juntos. (SAUL, Ana Maria. Entrevista. [fev. 2017]. Entrevistador: Fernanda dos Santos Paulo. Porto Alegre, 2017. 1 arquivo de 7 página transcritas).

Entender esse processo na dimensão ético-política colabora no entendimento da Educação Popular como concepção comprometida com a ocupação dos espaços. Isto é, uma Educação Popular como resistência disputando projeto de educação e de sociedade.

Sabemos que o conceito de Educação Popular é diverso, complexo e até divergente. Paulo (2018), por sua vez, apresenta um estudo sobre os sentidos e significados da Educação popular. Como exemplo do tensionamento:

Na suíça, Johann Heinrich Pestalozzi (1746-1827), por meio de cartas dirigidas a seus amigos (Enrico Gessner e o inglês James Pierpoint Greaves), escritas entre os anos de 1801 a 1809, discorria sobre suas ideias acerca da Educação Popular. O significado voltava-se para a instrução das crianças pobres, vinculado ao contexto de industrialização europeu, onde milhões de pessoas moravam nos subúrbios das grandes cidades, em condições de vida precárias. É, portanto, nessas cartas, que ele faz menção a respeito da Educação Popular com —conteúdo extremamente biográfico. (SOËTARD, 2010, p.41). Isso, porque ele escreve nas cartas as suas experiências profissionais, sendo que uma delas tratava do projeto de criação de uma escola profissional para os pobres, o qual era considerado como Educação Popular. Sob este prisma, na minha interpretação, o sentido da Educação Popular, para Pestalozzi, é de cunho assistencialista. (PAULO, 2018, p. 178-179).

O entendimento da Educação popular faz esse campo de conhecimento teórico-prático ser interpretado de múltiplas formas, de acordo com as influências teórico-metodológicas. Na trajetória teórico-prática da pioneira da Educação popular freiriana, a sua contribuição, neste sentido, para a história da Educação popular e para a universidade é justamente, dentro desse debate acerca da Educação Popular, fazer desta uma práxis com vistas à transformação da educação e da sociedade. "Eu 
sinto que a minha prática tem sido orientada pelos princípios de Educação Popular que Paulo Freire propôs. ${ }^{68 "}$

Figura 4: Entrevista com Ana Maria Saul.

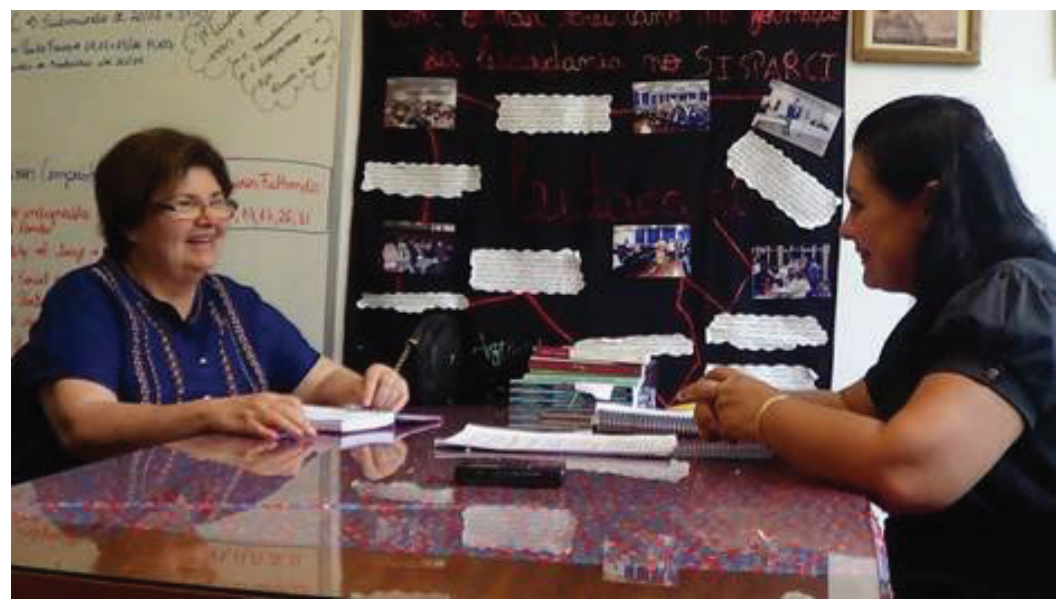

Fonte: Paulo (2018).

A humildade intelectual e compromisso com a rigorosidade metodológica é testemunhada na entrevista realizada com a professora, cujo trabalho teórico-prático é reconhecido e respeitado entre os seus pares. Entretanto, apesar da longa trajetória profissional, seu trabalho carece de maior reconhecimento no âmbito acadêmico. Constatamos, com isso, que mulheres intelectuais da Educação Popular ainda são pouco reconhecidas como intelectuais e o reconhecimento, até então, é exclusivo e restrito a pequenos grupos.

A docência universitária de mais de quarenta anos e os impactos de suas pesquisas educacionais para a educação faz com que a educadora seja reconhecida como pioneira da Educação Popular freiriana. Ela apresenta, a partir da sua experiência profissional, originária de movimentos de Formação política, como no movimento estudantil, uma epistemologia das práxis. 
A contribuição de Paulo Freire em sua formação é percebida na entrevista, nas suas publicações e em seus estudos. Para a educadora, o educador lhe ensinou que ser professor e professora é estar e ser comprometido, que somos seres do e com o mundo; portanto, somos sujeitos interventivos. Isto é, somos "um ser do trabalho e da transformação [...]" (FREIRE, 1992, p. 28).

Saul (1988) apresenta Freire como uma referência importante na perspectiva crítico-transformadora, sobretudo a partir dos conceitos de diálogo, de conscientização e de criação coletiva no que caracteriza como avaliação emancipatória. A avaliação emancipatória é um dos temas trabalhado pela educadora. Para ela, a avaliação dialógica e mediadora serve para a intervenção do professor em sua prática profissional. É um processo de descrição, análise e crítica de uma dada realidade, visando transformá-la, situada numa vertente libertadora. No Dicionário Paulo Freire, Saul (2010), especificamente no verbete currículo, dá indicações da perspectiva da Educação Popular, na sua acepção de política crítico-transformadora, cuja defesa é a educação libertadora.

\section{Maria Lacerda de Moura (1887-1945): Educação Iguali- tária de mulheres e homens.}

Maria Lacerda de Moura nasceu em Minas Gerais, no dia 13 de maio de 1887, e desde jovem se interessou pelo pensamento social e pelas ideias anticlericais. Formou-se pela Escola Normal de Barbacena e em 1904 começou a lecionar na mesma escola.

Segundo Eggert e Pacheco (EGGERT; PALHECO, 2010), Moura publicou em 1918 a obra Em torno da educação e, em 1919, Renovação, estabelecendo contato com jornalistas em Minas Gerais, São Paulo e Rio de Janeiro.

[...] em 1920 fez sua primeira conferência fora de Barbacena e daí até sua morte, em 1945 fez uma longa lista de conferências e uma intensa produção intelectual materializada em livros e artigos publicados [...] foi atuante no cenário político de seu tempo ao debater por escrito com comunistas, anarquistas, feministas, educadores, democratas, jornalistas. [...] Mudou-se para São Paulo em 1921 e 
junto com algumas militantes anarquistas fundou a Federação Internacional Feminina, cuja proposta era discutir questões relativas à mulher e à criança, de modo a transformar as relações sociais capitalistas, lutando pelo direito ao voto e outras medidas (EGGERT; PALHECO, 2010, p. 199).

Maria Lacerda de Moura pode ser considerada também uma das pioneiras do feminismo no Brasil, bem como a professora que defendia uma pedagogia feminista.

Figura 2: Maria Lacerda de Moura

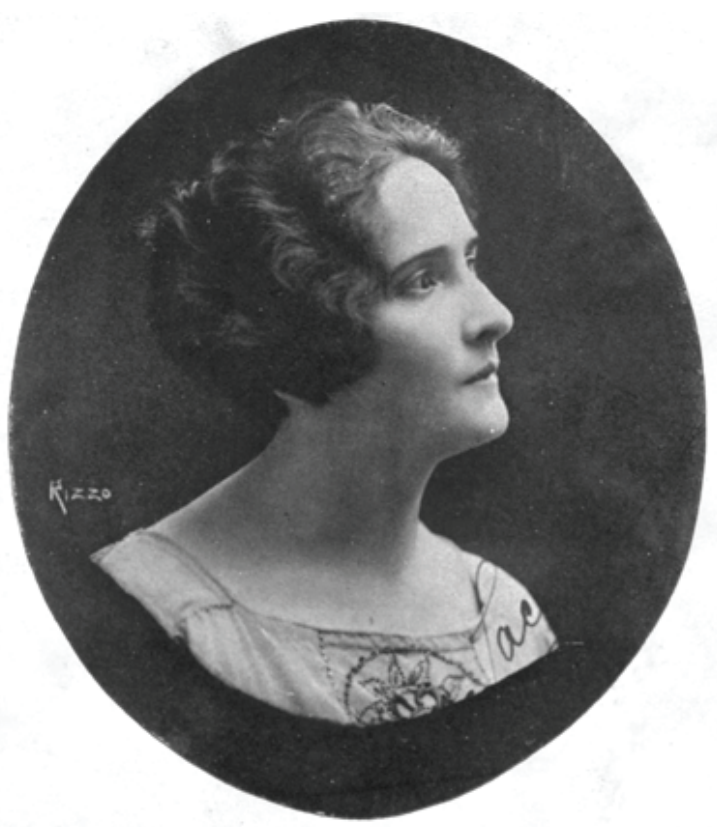

Fonte:https://www.google.com/search?biw $=1366 \&$ bih $=576 \&$ tbm $=$ isch\&sa $=1 \&$ ei $=$ N0ldXfmEL5e65OUP2y82AI\&q=Maria +lacerda + de + Moura $+\& o q=$ Maria + lacerda + de + Moura $+\& g s \_1=i m g .3 . .012 j 0 i$

Seu pensamento pedagógico era voltado para a luta contra o analfabetismo. A professora, desde 1904, trabalhou intensamente com a questão da educação, colaborando para fundar a liga contra o analfabetismo, em Barbacena, em 1912. "Educadora, convicta de que a educação é uma força revolucionária e de que sua missão seria de exercê-la" (LEITE, 2005, p.15). 
Ainda que tenha renegado a escola oficial [...] conferencista ativa, tratava de temas como educação, direitos da mulher, amor livre, combate ao fascismo e antimilitarismo [...] se posicionou contra o movimento feminista sufragista [...] passou a compreender que a conquista dos direitos políticos serviriam a uma elite feminina, e que, portanto, tanto as mulheres ricas quanto as pobres permaneceriam com escravas seculares. [...] compreendia que as desigualdades sociais existentes entre os gêneros e as condições em que se encontravam as mulheres resultavam da diferente educação que tinham acesso, tanto escolar como não escolar. [...] defendia o controle da natalidade pelas mulheres, através da maternidade consciente, independência financeira, e era contrária ao amor único [...] (EGGERT; PALHECO, 2010, p. 200-201).

No seu mais lido e famoso texto Das vantagens da educação intelectual e profissional da mulher na vida prática das sociedades, Moura afirmou que

A vida social exige no homem e na mulher características especiais, atributos bem definidos a fim de assegurar o bem estar coletivo. $\mathrm{O}$ homem nasce com qualidades indispensáveis aos feitos de homem. A mulher tem em si o gérmen hereditário para preencher suas funções. Pondo de parte, porém a questão dos sexos, a multiplicação da espécie, pergunta-se, uma humanidade só de homens seria completa? Da mesma forma raciocinaremos com relação à mulher: fariam elas mundo harmonioso no seu conjunto?"(MOURA, 2010, p.95)

A pensadora também questiona e propõe a obra a reflexão no sentido de uma educação feminista, apesar de não ser esta sua pauta central. Para ela a mulher nasceu, socialmente falando, mulher antes de esposa e mãe, assim como o homem nasce "sábio ou generoso, filósofo ou operário, político ou guerreiro, inventor ou andarilho, independente das funções de pai". E por que razão nos dizem com arrogância axiomática: a mulher nasceu para esposa e mãe, para o lar? Se o homem, socialmente falando, tem fins de preencher independente do sexo, a mulher não menos, é claro. A enfermeira, a operária, a cientista, a escritora, a professora, a médica, a farmacêutica, a diplomata, a filantropa, a diretora de hospitais e creches, etc., entregar-se-á mais bem aos deveres se não tiver filhos (LEITE, 2005, s/p).

\section{Segundo Moura:}

[..] a obra da educação científica racional para ambos os sexos, é $\mathrm{o}$ mais perfeito instrumento de liberdade. E a extinção da miséria 
universal, é o acúmulo de riquezas, é a contribuição para a solidariedade - a moral do futuro. [...] Faz desaparecer o preconceito de classes, elevando o respeito a verdade, o benefício coletivo. [...] Desde a escola primária, o objetivo da educação, como dizia Diderot - é a utilidade (Moura, 2010, p.206).

Nesse sentido, no seu pensamento, não poderá existir nunca a igualdade natural - é lógico, e ninguém tem a pretensão de ir contra as leis naturais - é a harmonia em uma aparente desarmonia.Para esse sistema, sua inferioridade é apenas econômico-social, inferioridade de preconceito. "Os séculos de escravidão fizeram dela ente mais fraco física e mentalmente. [...] a deseducação feminina tem retardado a civilização" (EGGERT; PALHECO, 2010, p.207).

Em notas de conclusão, podemos considerar a educação atual incapaz de lhe desenvolver aptidões e faculdades latentes - deseduca, continua o prejuízo tradicional, considerando que o progresso depende das duas facções humanas -, o homem só poderá atingir o apogeu da sua grandeza intelectual e moral quando a mulher tiver clarividência moral. Assim é indispensável a revolução na educação, a fim de ruir todo edifício antigo e reconstruir novos alicerces mais sólidos, racionais, científicos. "[...] Socialmente falando, é fator da civilização moral: deve caminhar e fazer caminhar a Humanidade em busca da Beleza e da Verdade, que seu cérebro ainda lhe não deixou entrever" (Moura, 2010, p. 209).

\section{Referências:}

EGGERT, E; PALHECO, O. Maria Lacerda de Moura e a educação libertária para mulheres. In: Fontes da pedagogia latino-americana: uma antologia. Belo Horizonte: Autêntica Editora, 2010. p.199 -209 .

FLORESTA, Nísia. Opúsculo humanitário. Introdução e notas de Peggy Sharp-Valadares. Posfácio de Constância L. Duarte. São Paulo: Cortez, 1989. In: ROSA, G. Nísia Floresta e a reforma na educação em busca da equidade de gênero. Fontes da pedagogia latino-americana: uma antologia. Belo Horizonte: Autêntica Editora, 2010. P. 95-101.

FREIRE, Paulo. Extensão ou comunicação. 10 ed. Rio de Janeiro: Paz e Terra, 1992. 
ITAQUY, Antônio Carlos de Oliveira. Nísia Floresta: Ousadia De Uma Feminista No Brasil Do Século XIX. Porto Alegre: Universidade Regional do Nordeste do Estado do Rio Grande do Sul, 2013.

LEITE, Miriam Lifchitz Moreira. Maria Lacerda de Moura, uma feminista utópica. Florianópolis: Mulheres; Santa Criz: EDUNISC, 205, apud EGGERT, E; PALHECO, O. Maria Lacerda de Moura e a educação libertária para mulheres. In: Fontes da pedagogia latino-americana: uma antologia. Belo Horizonte: Autêntica Editora, 2010. p.199-209.

MOURA, Maria Lacerda de. A mulher é uma degenerada? Das vantagens da educação intelectual profissional da mulher na vida prática das sociedades. In: EGGERT, e PALHECO, Maria Lacerda de Moura e a educação libertária das mulheres. Fontes da pedagogia latino-americana: uma antologia. Belo Horizonte: Autêntica Editora, 2010. P. 199-210.

PAULO, Fernanda dos Santos. Pioneiros e pioneiras da Educação Popular freiriana e a universidade. Tese (Doutorado) - Universidade do Vale do Rio dos Sinos, Programa de Pós-Graduação em Educação, São Leopoldo, RS, 2018. 268 f.

SAUL, Ana Maria A. Avaliação emancipatória, desafio à teoria e à prática de avaliação e reformulação de currículo. São Paulo: Cortez/ Autores Associados, 1988.

SAUL, Ana Maria. Currículo. In: STRECK, Danilo; REDIN, Euclides; ZITKOSKI, Jaime José (Orgs.). Dicionário Paulo Freire. Belo Horizonte: Autêntica Editora, 2010.

SAUL, Ana Maria. Entrevista. [fev. 2017]. Entrevistador: Fernanda dos Santos Paulo. Porto Alegre, 2017. 1 arquivo de 7 página transcritas).

SEVERINO, Antonio Joaquim. Pressupostos filosóficos da formação e da prática do educador. Cadernos de Educação, Pelotas, FaE/UFpel, Ano 15, n. 27, p. 37-54, jul./dez. 2006. 